\title{
Ecology of tropical hermit crabs at Quirimba Island, Mozambique: niche width and resource allocation
}

\author{
David K. A. Barnes ${ }^{1,2, *}$, Sammy De Grave ${ }^{3}$ \\ ${ }^{1}$ Department of Zoology and Animal Ecology, University College Cork, Lee Maltings, Cork, Ireland \\ ${ }^{2}$ Frontier, The Society for Environmental Exploration, 77 Leonard St., London EC2A 4QS, United Kingdom \\ ${ }^{3}$ The Oxford Museum of Natural History, Parks Road, Oxford OXI 3PW, United Kingdom
}

\begin{abstract}
Intertidal-zone hermit crab populations in the Quirimba Archipelago occur in high densities and many species overlap considerably in terms of spatial distribution and types of shell used. The suites of shells used by 5 mid- to supra-littoral hermit crab species were studied (using multivariate analyses) across 3 shore zones, 7 islands and several levels of mollusc fishing pressure. Potentially high intra- and inter-specific competition for resources in the Quirimba Archipelago hermit crab assemblages is alleviated by a degree of macrohabitat and shore zone separation but largely by significant partitioning of shell resources. The suite of shells used by each species was distinct, even if certain types were in common. The highest influence on shell usage was tidal height followed by shore-zone area and hermit crab identity. Where the spatial distributions are tighter (in the supralittoral), the resource (shell) partitioning is greater. Fishing pressure (and associated abundance of target-species shells) was generally unimportant, but 1 species, Coenobita cavipes, used harvested shells opportunistically in proportion to their availability. Shannon $H^{\prime}$ and species-richness values of shells used increased with shore zone area in the upper shore zone but not in the supra-littoral zone. It is suggested that this was due to high fishing pressure on certain mollusc species making certain shells abundant for hermit crabs (shell middens were deposited on the supra-littoral zone). The results suggest a tight niche mosaic of the many hermit crab species in the Quirimba Archipelago.
\end{abstract}

KEY WORDS: Hermit crab $\cdot$ Niche width $\cdot$ Shell use $\cdot$ Resource partitioning

\section{INTRODUCTION}

Hermit crabs have been found to exhibit complex associations and mechanisms of inspection, selection, negotiation with their resource (gastropod shells), competitors (other hermit crabs) and shell epibionts (e.g. anemones or bryozoans). The charismatic nature of hermit crab interactions and their suitability for study of animal behaviour has led to a great variety and depth of study (e.g. Reese 1962, Vance 1972, Hazlett 1981, Bertness 1982, Gherardi 1990). Many

\footnotetext{
*E-mail: dkab@ucc.ie
}

aspects of the physical nature of shells influence selection by its user, but environmental conditions (e.g. anoxia see Côté et al. 1998) and user attributes (such as species, sex, size and behaviour) may also affect the choice of portable home (Reese 1962). As hermit crab species depend on the use of empty gastropod shells (buried empty shells and those of living gastropods are generally not procurable; see Kellogg 1976, Rutherford 1977), they are typically limited in supply (see e.g. Bertness 1980).

Potentially, a high variety of shell identities and the possibility of differential requirements by hermit crab species can explain the co-existence of many species (Gherardi \& Nardone 1997). The level of shell-resource 
partitioning in intertidal hermit crab communities and whether this does indeed alleviate inter-specific competition has been debated (Grant \& Ulmer 1975). Bertness (1981) and Hazlett (1981) considered that shell patterns and mobility were unlikely to reduce interspecific competition for shells when limited. Abrams (1980) and Leite et al. (1998) have suggested that differences in specific habitat preferences may alleviate competition pressures. In all likelihood, both shell-utilisation patterns and habitat preferences combine to alleviate inter-specific competition, as indeed has been demonstrated by Vance (1972) and Mitchell (1975). The variety of shore areas, habitats and islands in the Quirimba Archipelago have been suggested as important factors in reduction of inter-specific competition at the present study site (De Grave \& Barnes unpubl.).

Multivariate analyses have proven to be a popular and powerful way of investigating patterns in large data sets, which due to their size and/or complexity are difficult to analyse by univariate or graphical techniques. Unfortunately, such an approach has rarely been applied to hermit-crab resource-use, as shell usage and/or habitat partitioning have tended to be looked at in isolation. On many East African shores, however, species-rich intertidal assemblages of intertidal hermit crabs occur using a wide variety of shells (Gherardi et al. 1991, Gherardi \& Vannini 1992, 1993, Barnes 1997a, 1999). In the intertidal zone of the Quirimba Archipelago, northern Mozambique, 7 genera and 16 species of hermit crabs partially overlap in both space and resource use. Quirimba Island, one of the larger study islands, has a particularly high diversity of living gastropod molluscs and consequently hermitcrab use of this resource (Barnes 1999).

The combination of high diversity and abundance of intertidal zone molluscs and socio-economic conditions in Northern Mozambique has given rise to substantial artisanal harvesting of shore fauna (see Barnes et al. 1998). Gastropods are particularly important to such fisheries, and piles of empty shells (middens) are deposited on the supra-littoral or upper shore as a waste product. Such a local abundance of certain shell types and sizes potentially provides a resource free from the difficulties of procurement from either living molluscs or other hermit crabs. Typically being fresh from the removal of the living mollusc, midden shells tend to be in good condition, although the variety of species is both a reduced subset of the variety of local living gastropod species and varies between islands (Barnes et al. 1998).

In this paper, the diversity of individual hermit crab resources (mollusc shells) are examined in relation to shore height, area, habitat and island. In particular we ask: (1) Do shell-use patterns differ between islands which are in close proximity and similar in nature?
(2) Do shell-use patterns differ within species between shore heights? (3) To what degree do shore area, presence of mangrove swamps or human use of shell resources influence hermit-crab resource-use patterns? (4) What do shell-use patterns tell us about niche separation and competition for resources in the Quirimba Archipelago? (5) How do diversity and species richness of shells used vary between shore types and island localities?

\section{MATERIALS AND METHODS}

Study site and protocol. The fieldwork was carried out from the Darwin/Frontier Mozambique station on Quirimba Island (northern Mozambique), between May and August of 1996 (for a map of the study area see Barnes 1997a, De Grave \& Barnes unpubl.). Hermit crabs were identified and counted along 3 transects from the supra-littoral to mid-shore zones of 8 islands of the Quirimba Archipelago. The shore was subdivided into the supra-littoral (above mean high water tide level, MHW, upper shore $(4+\mathrm{h}$ after low water to MHW) and mid-shore (4 to $2 \mathrm{~h}$ after low water), as described by Barnes (1997a). Lower shore and subtidal zones were not investigated, as hermit crab individuals are much less abundant, rendering these sampling areas inappropriate.

Ten random quadrats of $1 \mathrm{~m}^{2}$ were taken in each shore zone of each island and the numbers of individuals were pooled within the 3 transects (replicates) for each shore zone. The identity of gastropod shells used by each of the hermit crab species was established and quantified in each of the 3 zones. For each island the areas of each shore region were calculated from scale maps, as was the approximate region of mangrove forest (dominated by Rhizophora mucronata trees). The number of hermit crab species and shell identities was plotted against percent cover of distinct habitats. Commercially or artisanally important shells are harvested by islanders and left in middens which potentially increases availability of those shell identities. The importance of each gastropod shell identity (used by hermit crabs) to islanders was calculated from data in Barnes et al. (1998). Artisanal importance (of gastropods) was measured by the relative number of each shell identity collected by islanders (not in terms of commercial value or weight). Barnes et al. (1998) described quite different levels of harvesting for each shell identity on each of the study islands. The frequency of use (by hermit crabs) of such shell identities was measured by randomly sampling $>200$ individuals of each hermit crab species and recording the identity of the shell in use. These shell-use frequencies were compared to the 
differential importance of each shell identity to islanders for each island.

Statistical analyses. In order to investigate potential differences in shell-usage spectra, the data sets were subjected to univariate and multivariate analyses techniques. Several measures of diversity were calculated: total number of shell species utilised per hermit crab species; Shannon $H^{\prime}$ (using $\log _{10}$ ); Pielou's evenness measure; Simpson's dominance index; and Hill's numbers $N_{1}$ and $N_{2}$ (for a discussion of the use of the latter indices in ecology see Hill 1973). Values resulting from these calculations represent mean values of 3 replicate samples per tidal zone per island. This data set was also subjected to canonical correspondence analysis (CCA) (ter Braak 1986), with data transformed by $\ln (x+1)$ in order to reduce the statistical weight of abundant species relative to rarer species. This particular type of ordination method aims at producing a low-dimensional ordination space, in which the observed axes are a linear interpretation of the species-environment relations. In order to study the relative importance and interactions of environmental and biotic variables and fishing pressure on shellusage patterns, an environmental variable-station matrix was constructed. This comprised the various hermit crab species (7 species, binary coded per species); percentage cover within each tidal zone of mangroves, sand, seagrass, rocks and reef; island size (arbitrarily ranked from 1 to 6, with largest island coded 1 and smallest coded 6); tidal height (coded 1 to 3, from mid-tide level [1] upwards); total fishing pressure (arbitrarily ranked from 1 to 6 based on data in Barnes et al. 1998); and species-specific fishing pressures for 12 species of gastropod (details in Table 2 of Barnes et al. 1998). Using the same shell usage data set, 3 different CCA analyses were performed by varying the environmental variable data set. In the first analysis (CCA 1), only the following variables were included: the hermit crab identities, the various habitat types, island size, tidal height and total fishing pressure. A second analysis (CCA 2) was run on the same data sets, but substituting total fishing pressure by the various species specific-fishing pressures. In the third analysis (CCA 3), all variables except the species-specific fishing pressures were treated as covariables. This procedure effectively partials out the effects of the covariables (see ter Braak 1988).

\section{RESULTS}

\section{Niche separation}

The 7 species of hermit crab in the middle, upper and supra-littoral zones of the Quirimba Archipelago used a total of 37 species of gastropod shells. Although a high proportion of shell identities were common to many hermit crab species, even to the degree of, for instance, the mollusc Thais savignyi being utilised by all species, the suite of shells used exhibited distinct species-specific separation, as exemplified by the nonoverlapping nature of the polygons uniting all samples of any given species (Fig. 1). Only the first 2 extracted axes were considered for interpretation of this analysis, as the higher axes did not contribute significantly to the underlying structure, in terms of the cumulative variance explained (CCA 1: Table 1). The last 2 axes extracted (Axes 3 and 4), for example, only contributed a further $17.7 \%$ of the total variance explained $(75 \%$ :

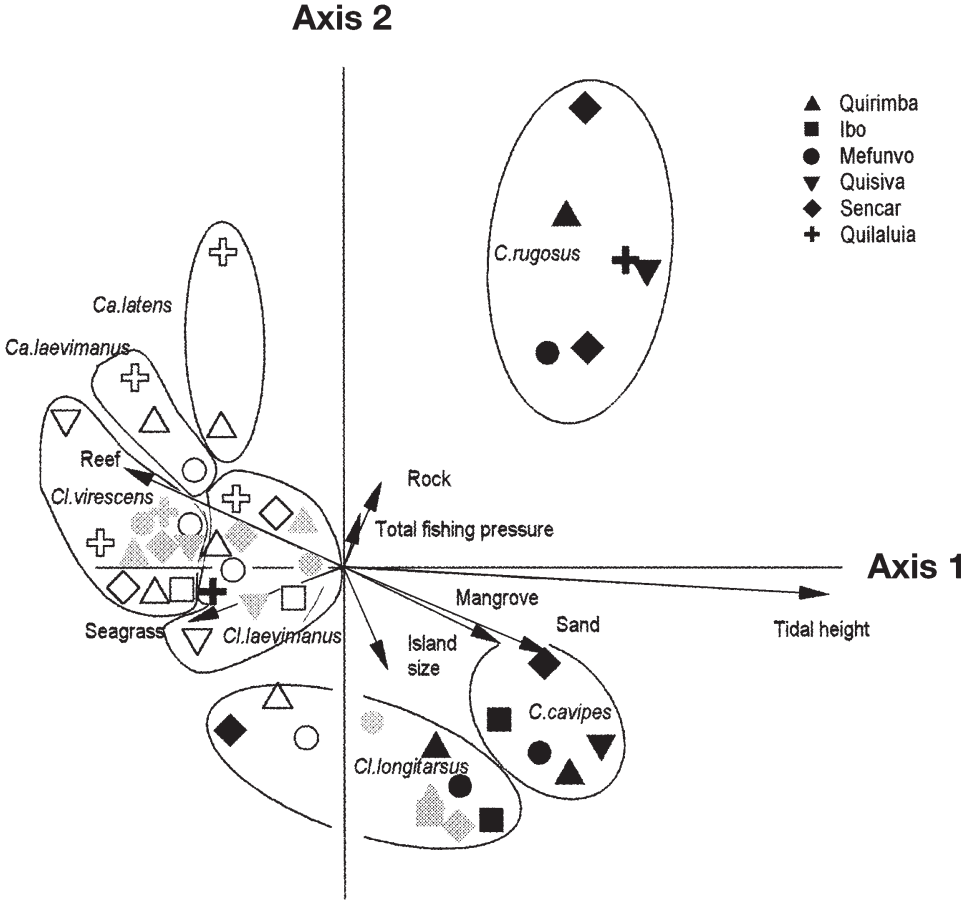

Fig. 1. Hermit crab species of genera Coenobita, Calcinus and Clibanarius Canonical correspondence analysis (CCA 1). Positions of samples are indicated and coded according to island (see key) and tidal height (black: supra-littoral, grey: upper, open: mid). Centroids of hermit crab species (treated as environmental variables) are indicated by position of their names, as are continuous environmental variables (arrows). Enclosed polygons are all samples of any given species. C. cavipes: Coenobita cavipes; C. rugosus: Coenobita rugosus; Ca. laevimanus: Calcinus laevimanus; Ca. latens: Calcinus latens; Cl. laevimanus: Clibanarius laevimanus; Cl. longitarsus: Clibanarius longitarsus; $C l$. virescens: Clibanarius virescens 
Table 1. Eigenvalues, species-environment correlations and percentage variance of canonical correspondence analyses for all 3 analyses (see 'Material and methods' for details)

\begin{tabular}{|c|c|c|c|c|}
\hline & Axis 1 & Axis 2 & Axis 3 & Axis 4 \\
\hline \multicolumn{5}{|l|}{ CCA 1} \\
\hline Eigenvalue & 0.39 & 0.15 & 0.09 & 0.08 \\
\hline Species-environment correlations & 0.98 & 0.93 & 0.90 & 0.90 \\
\hline Cumulative percentage variance of species data & 24.3 & 33.9 & 39.6 & 44.4 \\
\hline Cumulative percentage variance of species-environment relation & 41.0 & 57.3 & 66.9 & 75.0 \\
\hline \multicolumn{5}{|l|}{ CCA 2} \\
\hline Eigenvalue & 0.40 & 0.17 & 0.11 & 0.09 \\
\hline Species-environment correlations & 0.99 & 0.96 & 0.96 & 0.95 \\
\hline Cumulative percentage variance of species data & 25.1 & 35.5 & 42.2 & 47.7 \\
\hline Cumulative percentage variance of species-environment relation & 32.1 & 45.4 & 53.9 & 61.0 \\
\hline \multicolumn{5}{|l|}{ CCA 3} \\
\hline Eigenvalue & 0.10 & 0.06 & 0.05 & 0.04 \\
\hline Species-environment correlations & 0.86 & 0.82 & 0.84 & 0.82 \\
\hline Cumulative percentage variance of species data & 9.6 & 15.2 & 19.7 & 23.2 \\
\hline Cumulative percentage variance of species-environment relation & 27.5 & 43.5 & 56.5 & 66.5 \\
\hline
\end{tabular}

Table 1). Coenobita rugosus, the most terrestrial of the studied decapod species, had a clearly different shellusage pattern from any of the other species (Fig. 1). Also, the decapods Clibanarius longitarsus and Coenobita cavipes, mainly upper- to supra-littoral species, had distinct shell-usage patterns that were however very close to each other. The other decapod species (Clibanarius laevimanus, Clibanarius virescens, Calcinus laevimanus, Calcinus latens) exhibited only a minor shell-usage segregation pattern, although within this broad grouping, each species remained distinct. The first axis is clearly related to tidal height, with mangrove and sand percentage cover following the same trend and reef and seagrass cover showing the opposite trend. This is clearly the main underlying structure in the data set, explaining the segregation of shell usage by the supra-littoral and upper-littoral species from that by the upper- to mid-littoral species. As the second CCA axis is not clearly related to any of the environmental variables (low intra-set correlations for second axis in CCA 2), the distinct separation of Coenobita rugosus from the other supra-littoral hermit crab species is not immediately obvious, but in all likelihood is due to biological qualities (e.g. inter-specific competition), rather than environmental variables structuring this segregation.

\section{Species-area relationships}

Island (or shore zone) size also had a high influence on the particular suite of shells used by hermit crabs (Table 2). In addition to relationships with particular shell identity use, the actual number of different gas-
Table 2. Intra-set correlations between environmental variables and the first 2 canonical correspondence analysis axes for CCA 2 analysis (see 'Materials and methods'). Hermit crab species, substrate characteristics, island size, and fishing pressure characteristics were used as environmental variables

\begin{tabular}{|lrr|}
\hline Variable & Axis 1 & Axis 2 \\
\hline Hermit crab species & & \\
Coenobita cavipes & & \\
Coenobita rugosus & 0.455 & -0.341 \\
Clibanarius longitarsus & 0.583 & 0.706 \\
Clibanarius virescens & 0.211 & -0.493 \\
Clibanarius laevimanus & -0.554 & 0.082 \\
Calcinus latens & -0.330 & -0.041 \\
Calcinus laevimanus & -0.190 & 0.201 \\
& -0.162 & 0.027 \\
Environmental variables & & \\
Island size & & \\
Tidal height & 0.840 & -0.165 \\
\% mangrove cover & 0.880 & -0.020 \\
\% sand cover & 0.292 & -0.075 \\
\% rock cover & 0.378 & -0.114 \\
\% seagrass cover & 0.072 & 0.113 \\
\% reef cover & -0.286 & -0.046 \\
& -0.041 & 0.550 \\
Species-specific fishing pressures & & \\
Chicoreus chicoreus & & \\
Chicoreus ramosus & 0.239 & -0.208 \\
Cypraea tigris & 0.601 & -0.033 \\
Fasciola trapezium & 0.303 & 0.149 \\
Harpa major & 0.301 & -0.109 \\
Lambis lambis & -0.146 & 0.036 \\
Mitra mitra & 0.073 & -0.199 \\
Strombus mutabilis & 0.300 & -0.093 \\
Terebralia palustris & 0.323 & -0.060 \\
Turbo coronatus & 0.488 & -0.209 \\
Vassum turbinellum & 0.280 & -0.129 \\
Volema paradisica & 0.355 & 0.001 \\
& 0.476 & -0.194 \\
& & \\
\hline
\end{tabular}


tropod shells used by each hermit crab species was also related to (log) shore-zone size (Fig. 2a). As would be intuitively expected and predicted by classical island biogeography, the number of shells used increased with zone area, irrespective of hermit crab species identity. Significantly more shells were used in the upper and supra-littoral zones than in the middle shore per unit area (general linear model, ANOVA, $F=118, \mathrm{p}=0.001$ ). There was a similar relationship between the area of mangrove forests and the proportion of gastropod shells that were mangrove dwellers used by hermit crab species (Fig. 2b). Hermit-crab use of gastropod shells of mangrove-dwelling origin peaked at just over $40 \%$ of individual shells (shell abundance) and just over $25 \%$ of shell identities (shell species), but were zero in areas without mangrove forests.

\section{Species-artisanal use relationships}

Total fishing pressure does not account for much of the variability in the data set (Fig. 1), in all likelihood because of the very distinct shell-usage pattern of specific hermit crab species. To further explore the importance of fishing pressure, a further CCA was run (Table 2), in which total fishing pressure was substituted by species-specific fishing pressure. Only the first axis was considered for interpretation, as it explains $>50 \%$ (i.e. $32.1 \%$, compared with $61 \%$ for Axis 4 ; Table 1) of the total species-environment relationship explained (CCA 2; Table 1). This axis is clearly related to tidal height and island size. Surprisingly, on a par with some of the hermit crab identities, the next most important variable is the species-specific fishing pressure of the mollusc Chicoreus ramosus. This was a species with a high degree of fishing pressure and a shell that was heavily exploited by both the decapods Coenobita cavipes and C. rugosus (but not by other hermit crab species). Similarly, the species-specific fishing pressure of the molluscs Terebralia palustris and Volema paradisica, both species with high fishing pressure and used by both Coenobita species (although not so exclusively), also exhibited high intraset correlations between these variables and the first CCA axis. In view of the high intra-set correlations of some of the species-specific fishing pressure, which are of the same order of magnitude and even higher than some of the environmental variables, it can be concluded that species-specific fishing pressures are equal in importance in structuring shell usage by the hermit crab assemblage as the habitat types utilised.

To investigate further the structuring potential of artisanal fishing pressure on shell usage by the hermit crab assemblage studied, a partial CCA analysis was
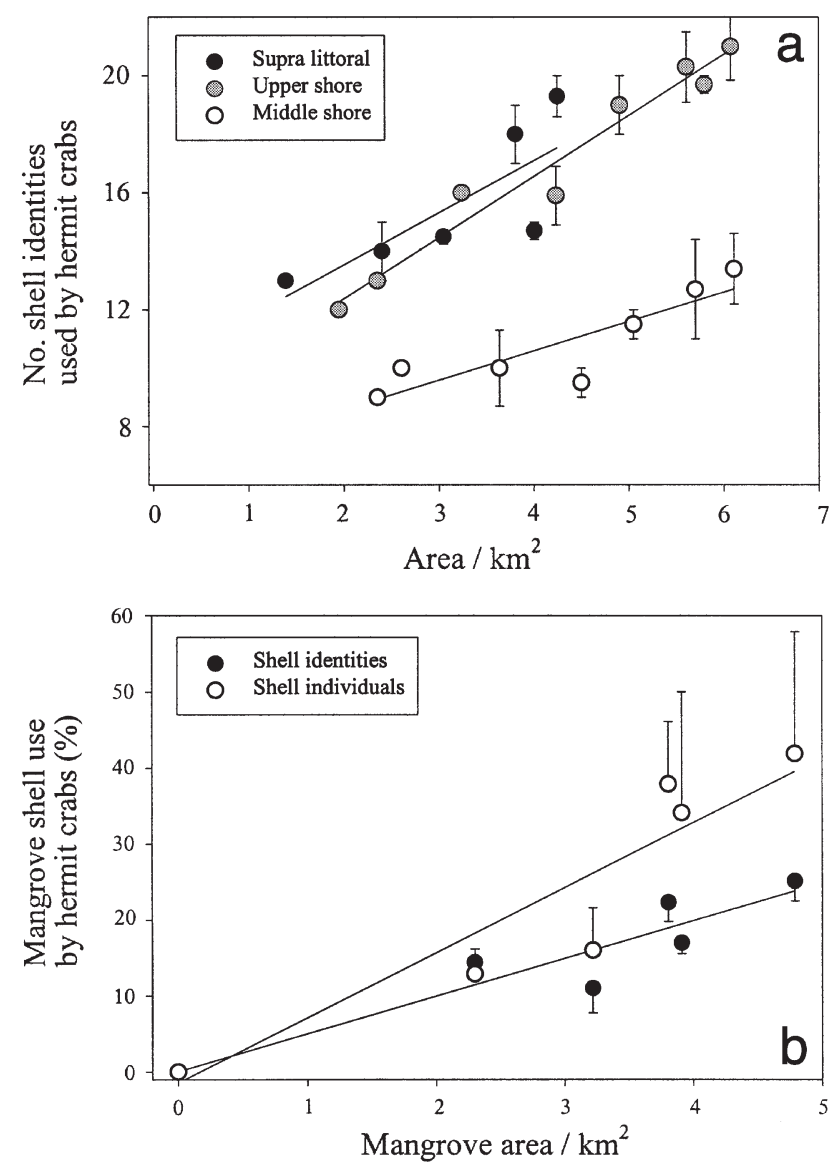

Fig. 2. Shell use by hermit crabs as a function of (a) shore and (b) mangrove area. All lines shown represent significant (ANOVA, all $\mathrm{p}<0.05)$ regression lines

run, with all environmental variables treated as covariables with the exception of species-specific fishing pressure (Fig. 3). The low eigenvalues and varianceexplained values (CCA 3: Table 1) indicate that the observed relationships are weak and should be interpreted with caution. Nevertheless, some structure can be observed. Strombus mutabilis, a seagrass-dwelling species of low fishing intensity is separated out from all other variables because of its unsuitability for hermitcrab use due to its shape, and is not considered further. The species-specific fishing pressures fall into 2 groups (Fig. 3), consisting of sand- or seagrass-dwelling species with a high degree of fishing pressure (e.g. Chicoreus ramosus) and reef- or mangrove-dwelling species with a medium to low degree of fishing pressure (e.g. Turbo coronatus). In all likelihood this reflects a harvesting pattern rather than structuring forces in shell usage of the community as a whole. Certain species may be deposited together in middens because they occur on the same or nearby islands or same tidal zones. The clearest (and only significant) 


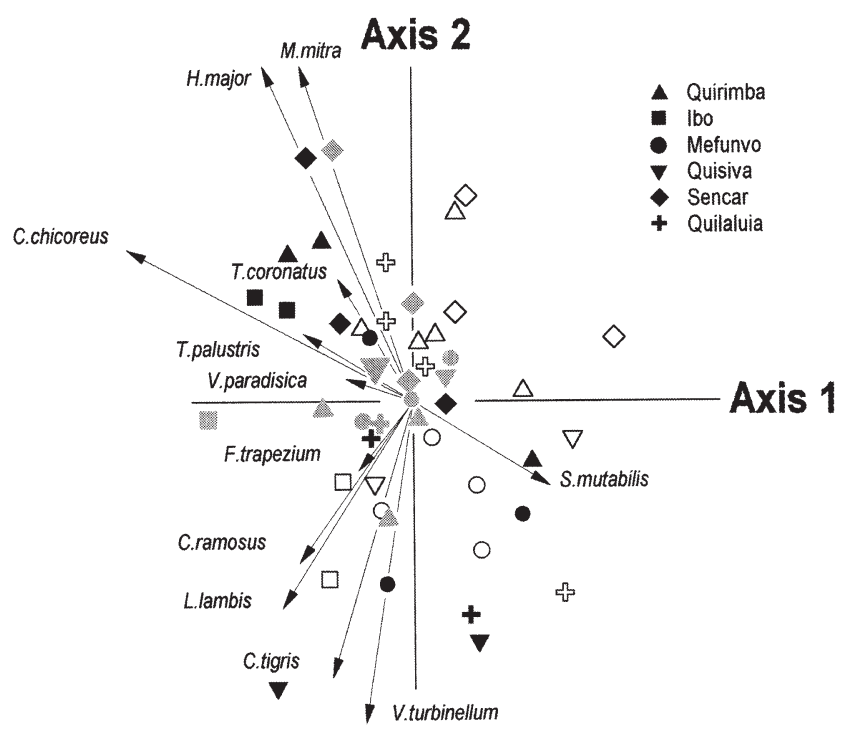

Fig. 3. Various species of gastropod molluscs. Canonical correspondence analysis (CCA 3). Positions of samples are indicated and coded as in Fig. 1. All environmental variables were treated as co-variables, except species-specific fishing pressure (indicated by arrows). Species names are given in full in Table 2

direct relationship of shell use with respect to availability from harvesting was exhibited by the hermit crab Coenobita cavipes (Fig. 4). Two shell identities, including $C$. ramosus, were unused by $C$. cavipes except when harvested.

\section{Diversity of shell types used}

All diversity indices followed the same trends, with evenness and dominance index also indicating the same trend. Thus, only information on Shannon $H^{\prime}$ and species richness is presented. The diversity of shells used in the supra-littoral zone ranged from Shannon $H^{\prime}$ values of 1.7 to 2.2 and species richness values from 11 to 16 (Fig. 5). There was no obvious across-species pattern in diversity although the values decreased with island (shore zone) area in Coenobita cavipes. All 3 supra-littoral hermit crab species did, however, exhibit the same species-richness pattern: increasing values peaking at the mid-sized island of Mefunvo but decreasing with larger zone area. Shannon $H^{\prime}$ values in the upper shore spanned a larger range than in the supra-littoral (1.5 to 2.4) as did the species-richness values (9 to 17). As in the supra-littoral zone, upper-shore Clibanarius longitarsus showed no pattern of Shannon $H^{\prime}$ values. The 2 other Clibanarius species in the upper shore, C. laevimanus and C. virescens, showed increasing values with increasing zone area. Only C. lae-

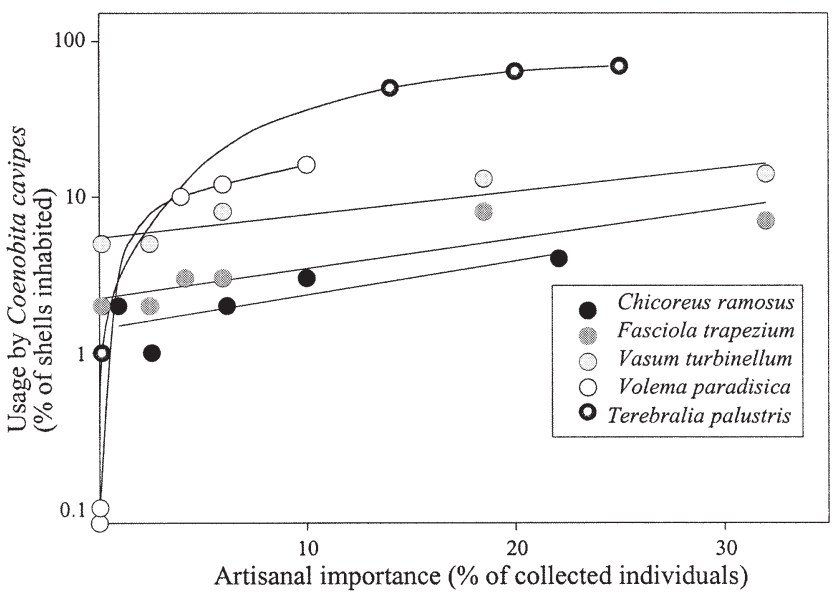

Fig. 4. Coenobita cavipes. Usage of shells with artisanal importance (Data for artisanal importance from Barnes et al. 1998)

vimanus showed a significant relationship in speciesrichness values, which increased with increasing size of zone. There were no obvious mid-shore relationships between diversity or species richness and zone area.

\section{DISCUSSION}

A fundamental question puzzling early ecologists was why there were apparently so many species in the tropics. Increased niche diversification (see SpencerDavies et al. 1971, Stoddart 1971) in complex tropical environments was initially considered to be important in diversity maintenance. Whether or not tropical niche diversification leading to specialisation is actually demonstrated by species has since been the subject of much debate (e.g. Connell 1978, Knowlton \& Jackson 1994). The detailed knowledge of hermit crab ecology, their high dependence on (species) specific discrete resources and heavily overlapping species requirements make the taxon highly interesting for studies of niche specialisation and resource partitioning (see e.g. Vance 1972, Abrams 1987, Gherardi 1990).

The diverse and abundant hermit crab assemblages that occur at Quirimba Island and other islands of the Quirimba Archipelago overlap spatially in both vertical (shore height) and horizontal (habitat types) planes on many shores (Barnes 1997a). As in a number of other East African localities studied to date (Vannini 1976, Gherardi \& Vannini 1992, Kalk 1995), the hermit crab assemblage may occur in very high but patchy densities. Unlike the situation at most localities, there are numerous species of hermit crabs (at least 16) in a small area, and they are generally not shell-restricted 

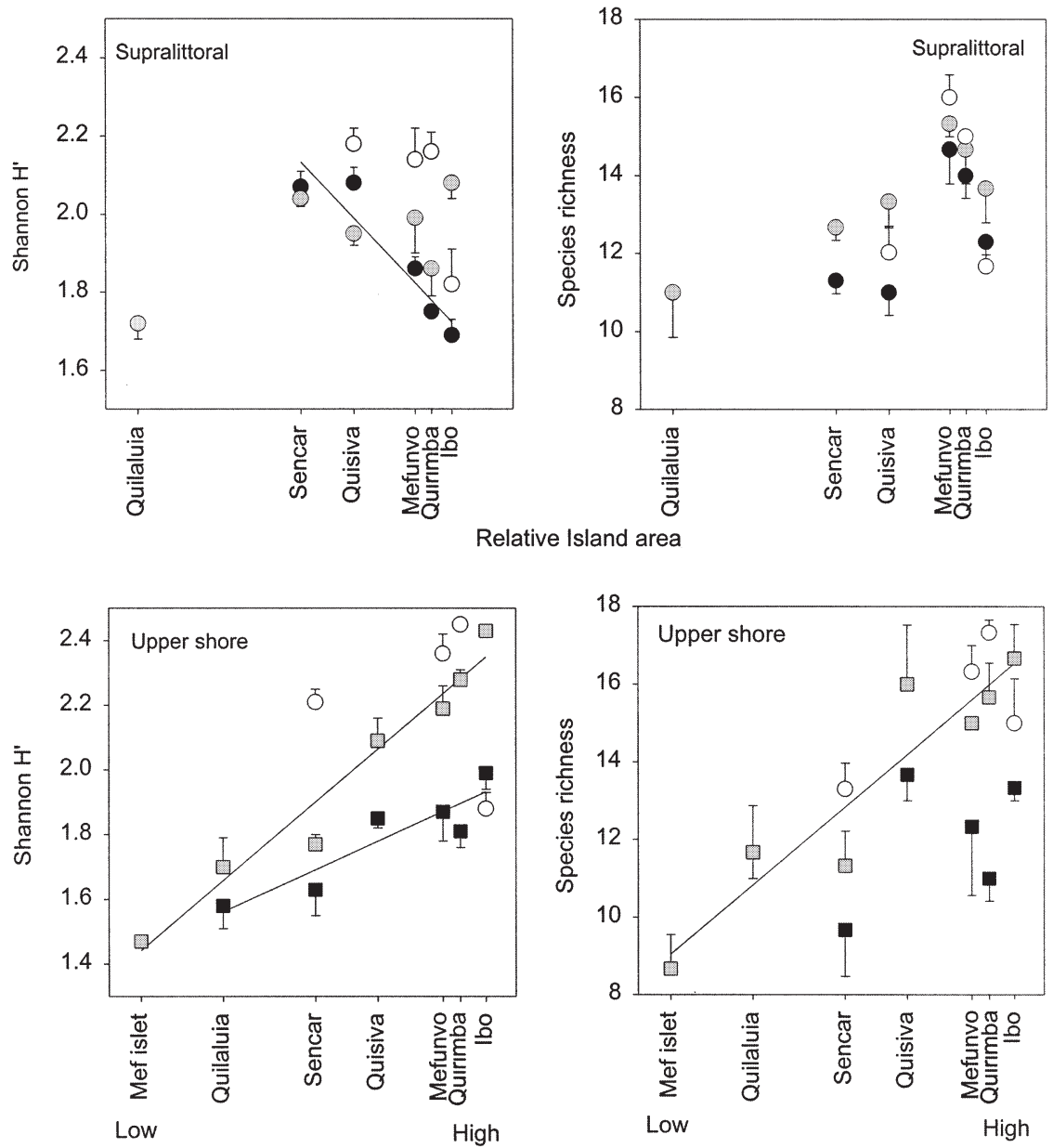

Relative Island area

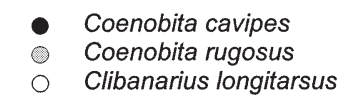

- Clibanarius virescens

$\square \quad$ Clibanarius laevimanus

Fig. 5. Shannon $H^{\prime}$ and species richness as a function of island area for 2 shore zones. Continuous $H^{\prime}$ lines: significant regression

(Barnes 1999). Increased availability and choice of shells coupled with similarly greater potential for microhabitat segregation may explain the increases in both individuals and species of hermit crab with increasing shore-zone area (at the Quirimba Archipelago) found by De Grave \& Barnes (unpubl.). This would support suggestions, by Abrams (1980) and Leite et al. (1998), that such segregation might alleviate competition pressures, thus allowing apparent specific co-existence and perseverance of individuals at high densities.

Although clear zonation and macrohabitat segregation patterns are exhibited by the Quirimba Archipelago hermit crab populations (Barnes 1997a, De Grave \& Barnes unpubl.), which probably reduce inter-specific competition to some extent, there is still consider- able spatial overlap in populations. The results of the present study suggest that shell segregation patterns may be more important in niche separation than habitat, despite the overlapping usage pattern of many shell identities by several different hermit crab species (Barnes 1999). Multivariate analyses showed the relative importance and interactions of the numerous factors responsible for the suites of shells used by each of the 5 species studied here, and that these had very different levels of importance (Fig. 1). As found by Bertness (1982) in Panama, the most important variable was shore height. Of more fundamental importance, however, was the discrete separation of the majority of hermit crab species (in terms of suites of shells used) despite their spatial overlap. The hermit crabs dwelling in the narrowest spatial zone, the supra-littoral, in 
which competition might be expected to be most intense, showed the greatest shell-suite separation. The largest shore zone (the mid-shore), in contrast, showed the tightest mosaic of shell-suite use. Although Barnes (1999) listed the largest number of shells as being used in the mid-shore zone, more are used in the supra-littoral and upper-shore compared to the area occupied by these zones (Fig. 2), an aspect not before considered. Clearly, the potentially high intra- and inter-specific competition for resources in the Quirimba Archipelago hermit crab assemblages is alleviated by a high degree of macro- and micro-habitat separation along the tidal gradient, but in addition by significant partitioning of shell resources. Furthermore, resources are more heavily partitioned where macro-habitat segregation is less distinct (or possible).

As with many tropical coastal localities around the globe, particularly in poorer African regions, there is a great deal of intertidal harvesting of molluscs at the Quirimba Archipelago for food (Barnes et al. 1998). This practice results in species-selective middens of shells being deposited on the higher levels of the shore, as cleaning of shells takes place at high tide. Hermit crabs are widely known to select shells based on many different attributes, such as mass (Reese 1962), size (Reese 1963), presence of epibionts (Jensen 1970), aperture characteristics (Vermeij 1976), centre of gravity and condition (Conover 1978), strength (Barnes 1999) and environmental factors. Shells available to hermit crabs may score very differently for one factor compared to another, so choice depends on a complex of factors, hence a large variety of cross-product interactions exists, such as hermit crabs at Quirimba Island choosing lighter shells with increasing shore height (Barnes 1999). The particular choice of shell may then influence later behaviour such as whether to burrow or climb trees as refugia (Barnes $1997 b$ ) or even the type of shell next chosen (Hazlett 1992). The superabundance of certain empty shells represents a further factor complicating potential choice. Shells chosen fell into broadly 3 categories (Fig. 3), but harvesting pressure of shell identities had little overall influence on selection by most hermit crab species (with the exception of Coenobita cavipes). In the narrow and densely populated zone of the supralittoral, it seems that hermit crabs had very different strategies. The use of shells by C. cavipes was generally in proportion to shell availability from harvesting (Fig. 4), although 2 shell identities were only used if harvested. The reasons for this are unclear but may be due to the high mass of both and of Terebralia palustris in particular (see Barnes 1999). The other 2 species of hermit crabs in the supra-littoral zone of the Quirimba Archipelago were not influenced significantly by harvesting pressure. As a result the 3 species in this zone, whilst all had substantial spatial overlap and used similar shell identities, were distinctly separate in proportional usage of shells. Coenobita rugosus used a distinctly different suite of shells from the other crabs whilst C. cavipes largely used harvested shells. In contrast, niche separation by Clibanarius longitarsus was mainly achieved through spatial segregation.

That Shannon $H^{\prime}$ and species-richness values of shells used increased with increasing island/shore zone area in the upper shore is not surprising (Fig. 5). In both these measures, there was, however, a decrease with increasing area in the supra-littoral. Such a counter-intuitive result may be explained by the higher fishing pressure on shell species on the larger islands. Higher fishing pressure results in a wider variety of species being used and more shell middens being deposited on the shore (Barnes et al. 1998). This influences uppershore species little and mid-shore species negligibly because middens are primarily deposited in the supralittoral, where harvesters have more time to deshell prey. There is, therefore, 2 gradients of variety of shell available to hermit crabs as a function of island or shore-zone size: a general increase in number of living gastropods with increasing area, and also greater supplies of monoshell-type middens on larger shores because of greater human activity.

The degree of niche differentiation and shell partitioning in the upper shore zones of the Quirimba Archipelago have made it possible for 3 supra-littoral species of hermit crabs to live in high densities with highly overlapping space and resource requirements. Where the spatial distributions are tighter (in the supra-littoral) the resource (shell) partitioning is greater. The lower shore and sub-littoral species of hermit crabs (in the Quirimba Archipelago) occur in much lower densities and appear to have much more overlapping shell usage (authors' pers. obs.) but as with sublittoral hermit crabs elsewhere have remained almost unstudied.

Acknowledgements. The authors wish to thank all the scientific staff, logistic staff and volunteer research assistants of the Darwin/Frontier Mozambique Marine Research Programme. This is a collaborative venture between the Society for Environmental Exploration (SEE) in the UK and the Ministépara a Coordenação de Acção Ambiental (MICOA) in Mozambique, and is partly funded by the Darwin Initiative for the Survival of Species (Department of the Environment, UK). We would also like to thank Dr D. Stanwell-Smith for being instrumental in the travel arrangements to Mozambique.

\section{LITERATURE CITED}

Abrams P (1980) Resource partitioning and inter-specific competition in a tropical hermit crab community. Oecologia 46:365-379

Abrams P (1987) Resource partitioning and competition for shells between intertidal hermit crabs on the outer coast of Washington State. Oecologia 72:248-258 
Barnes DKA (1997a) The ecology of tropical hermit crabs at Quirimba Island, Mozambique: distribution, abundance and activity. Mar Ecol Prog Ser 154:133-142

Barnes DKA (1997b) The ecology of tropical hermit crabs at Quirimba Island, Mozambique: vertical migration (tree climbing). Mar Ecol Prog Ser 158:233-240

Barnes DKA (1999) The ecology of tropical hermit crabs at Quirimba Island, Mozambique: shell characteristics and utilisation. Mar Ecol Prog Ser 183:241-251

Barnes DKA, Corrie A, Whittington M, Carvelho MA, Gell F (1998) Coastal shellfish resource use in the Quirimba Archipelago, Mozambique. J Shellfish Res 17:51-58

Bertness MD (1980) Shell preference and utilization patterns in littoral hermit crabs of the Bay of Panama. J Exp Mar Biol Ecol 48:1-16

Bertness MD (1981) Predation, physical stress, and the organisation of a tropical hermit crab community. Ecology 62: 411-425

Bertness MD (1982) Shell utilization, predation pressure, and thermal stress in Panamanian hermit crabs: an interoceanic comparison. J Exp Mar Biol Ecol 64:159-187

Connell JH (1978) Diversity in tropical rain forests and coral reefs. Science 199:1302-1310

Conover M (1978) The importance of various shell characteristics to the shell selection behaviour of hermit crabs. J Exp Mar Biol Ecol 32:131-142

Côté I, Bénédicte RU, Cooke PK (1998) Less choosy or different preference? Impact of hypoxia on hermit crab shell assessment and selection. Anim Behav 56:867-873

Gherardi F (1990) Competition and coexistence in two Mediterranean hermit crabs, Calcinus ornatus (Roux) and Clibanarius erythropus (Latreille) (Decapoda, Anomura). J Exp Mar Biol Ecol 143:221-238

Gherardi F, Nardone F (1997) The question of coexistence in hermit crab population ecology of a tropical intertidal assemblage. Crustaceana 70:608-629

Gherardi F, Vannini M (1992) Hermit crabs in a mangrove swamp: clustering dynamics of Clibanarius laevimanus. Mar Behav Physiol 21:85-104

Gherardi F, Vannini M (1993) Hermit crabs in a mangrove swamp: proximate and ultimate factors in the clustering of Clibanarius laevimanus. J Exp Mar Biol Ecol 168:167-187

Gherardi F, Micheli F, Vannini M (1991) Preliminary observations of the clustering behaviour of the tropical hermit crab, Clibanarius laevimanus. Ethol Ecol Evol 1:151-153

Grant WC, Ulmer KM (1975) Shell selection and aggressive behaviour in two sympatric species of hermit crabs. Biol Bull 146:32-43

Hazlett BA (1981) The behavioural ecology of hermit crabs.

Editorial responsibility: Otto Kinne (Editor),

Oldendorf/Luhe, Germany
Rev Ecol Syst 12:1-22

Hazlett BA (1992) The effect of past experience on the size of shells selected by hermit crabs. Anim Behav 44:203-205

Hill MO (1973) Diversity and evenness: a unifying notation and its consequences. Ecology 54:427-431

Jensen K (1970) The interaction between Pagurus bernhardus (L.) and Hydractinia echinata (Fleming). Ophelia 8: 135-144

Kalk M (1995) A natural history of Inhaca island. Witwatersrand University Press, Witwatersrand, Republic of S Africa

Kellogg CW (1976) Gastropod shells: a potentially limiting resource for hermit crabs. J Exp Mar Biol Ecol 22:101-111

Knowlton N, Jackson JBC (1994) New taxonomy and niche partitioning on coral reefs: Jack of all trades or master of some? Trends Ecol Evol 9:7-9

Leite FPP, Turra A, Gandolfi SM (1998) Hermit crabs (Crustacea: Decapoda: Anomura), gastropod shells and environmental structure: their relationship in southeastern Brazil. J Nat Hist 32:1599-1608

Mitchell KA (1975) An analysis of occupation by two sympatric species of hermit crab. I. Ecological factors. Biol Bull 149:205-213

Reese ES (1962) Shell selection behaviour of hermit crabs. Anim Behav 10:347-360

Reese ES (1963) The behavioural mechanisms underlying shell selection in hermit crabs. Behaviour 21:78-126

Rutherford JD (1977) Removal of living snails from their shells by a hermit crab. Veliger 19:438-439

Spencer-Davies P, Stoddart DR, Sigee DC (1971) Reef forms of Addu atoll, Maldive islands. In: Stoddart DR, Yonge CM (eds) Regional variation in Indian Ocean Reefs. Symp Zool Soc Lond 28:217-259

Stoddart DR (1971) Environment and history in Indian Ocean reef morphology. In: Stoddart DR, Yonge CM (eds) Regional variation in Indian Ocean Reefs. Symp Zool Soc Lond 28:3-11

ter Braak CJF (1986) Canonical correspondance analysis: a new eigenvector technique for multivariate direct gradient analysis. Ecology 67:1167-1179

ter Braak CJF (1988) Partial canonical correspondence analysis. In: Block HH (ed) Classification and related methods of data analysis. North Holland, Amsterdam, p 551-558

Vance RR (1972) Competition and mechanisms of coexistence in three sympatric species of intertidal hermit crabs. Ecology 53:1062-1074

Vannini M (1976) Field observations on the periodical transdunal migrations of the hermit crab, Coenobita rugosus Milne Edwards. Monitore Zool Ital 7:145-195

Vermeij GJ (1976) Interoceanic differences in vulnerability of shelled prey to crab predation. Nature 260:135-136

Submitted: April 5, 2000; Accepted: May 25, 2000

Proofs received from author(s): October 4, 2000 